\title{
The Tsavo Research Project
}

\author{
R. M. Laws
}

Dr Laws was the first Director of the Tsavo Research Project. This was started in February 1967 to investigate the habitat destruction in the Tsavo National Park, in Kenya, and the part played by the elephants which had been increasing rapidly-the research team's estimate was 23,000 in the park with an additional 12,000 in the peripheral areas, a total of $35,000 \pm 7,000$. After nine months the research programme, which included sample kills of elephants, was interrupted by the National Parks. Dr Laws spent the next eight months trying to restart the work and to discuss his findings and proposals; no discussions took place and he resigned. The article here consists of part of a paper (slightly amended by Dr Laws) published in the fournal of Reproduction and Fertility, Supplement No 6, 1969, and reproduced by permission. It explains why he regards the sample cropping as essential to find out what is happening in the elephant populations, and whether they are regulating their numbers quickly enough to save the habitat. Since Dr Laws left the Tsavo in June 1968, the Research Project has been carried on under the direction of the Botanist Warden, Dr P. E. Glover, an article by whom appeared in the September ORYX, page 323; a comment on this by Dr Laws will appear in the next ORYX, May $197 \mathrm{r}$.

Essentially the problem is that the habitat in the Tsavo National Park is changing from Commiphora-Acacia bush to open grassland, and unless management is successfully undertaken this trend is likely to continue. Although the initial effect was to increase the ecological diversity of the area, and to improve it for tourist viewing, the diversity is now rapidly decreasing and the problem is how to stop this change before the present diversity is lost. The Tsavo Research Project was initiated to investigate the problem, with the support of the Kenya Government and the Ford Foundation.

There are some ten elephant populations in the ecological unit which extends over some 17,000 square miles. They are characterised by separate distributions and (so far as it has been possible to study them) differing populations parameters. By comparing the results of investigations into their social structure, reproduction, growth, age structure and mortality, with comparable studies carried out in Uganda it is shown that natural regulatory processes are only just beginning to come into play in Tsavo, although the habitat change is far advanced. The nature of the hypothetical elephant-vegetation-climate cycle is discussed and it is suggested that what is usually taken to be the beginning of an elephant problem is often almost the end of the bush-to-grassland cycle. By comparison with western Uganda it may take 15 to 20 years for full regulatory changes to come into operation; by then it is probable that, 
in the absence of management, the habitat of the Tsavo National Park will have irretrievably changed over most of the area, to grassland or to desert, depending on the climatic trend over the next decades.

The Tsavo ecological unit is undergoing a progressive cycle of change from bush to grassland. Up to I5 years ago the vegetation was almost entirely dry Commiphora-Acacia bush, but under the influence of elephant and fire, the bush has been thinned or destroyed over large areas, particularly in the vicinity of rivers and artificial dams, where it has been replaced by grassland. This is undisputed. There was, at least initially, an improvement in the balance of diversity, because, although no new species are likely to have entered the system, there has been an increase in the vegetation and fauna characteristic of the grassland habitat. It is still not known how stable this grassland may be in an area which receives an erratic rainfall, with rigorous annual and seasonal fluctuations. Nor is it possible to predict future climatic trends.

It is probable that diversity is now decreasing and if the present habitat trend continues, grassland will probably come to predominate, to the almost complete exclusion of bush, over very wide areas. The rate of change to grassland, accelerated by fire, has been very rapid and any subsequent reversal to bush, if it occurred, would probably be much slower. There is an inherent danger in large oscillations of 'island' populations and a possibility of the elimination of some species (trees, bushes and other plants, as well as invertebrate animals, amphibia, reptiles, birds and mammals). With current trends in land-use in the surrounding areas the probability of recolonisation by outside populations is decreasing, particularly in the case of the animals. With each year that goes by the chances of stopping or reversing the habitat change diminish, and it is now nine years since the problem was first discussed by the Board of Trustees.

\section{Human Pressure}

Although it is very likely that similar changes have occurred in the past, with cycle lengths of 100 years or more, a major factor which now inhibits the continuance of natural cycles is the rapid expansion of human populations. Natural areas are now limited and increasingly influenced by the changing ecology of the areas surrounding them. Once the boundaries are defined National Park ecosystems are no longer natural and there is a strong case for management. It has been suggested that "you could achieve exactly what is happening in Tsavo with fire alone-without the help of elephant, that is" (Harthoorn, 1966). But this is precisely what range management bush clearing schemes aretrying to do elsewhere with great difficulty (e.g. Pratt, I966), doubtless wishing they could use elephants instead of machinery.

Fire has also been a factor in the past, although it may have increased in incidence with the advent of the safety match and the bicycle. In many areas forest or woodland continues to expand in the face of regular burns, yet I know of no case where this is happening in competition with dense elephant populations. The Budongo Forest for example, is slowly moving south-westerly, the north-western border retreating 


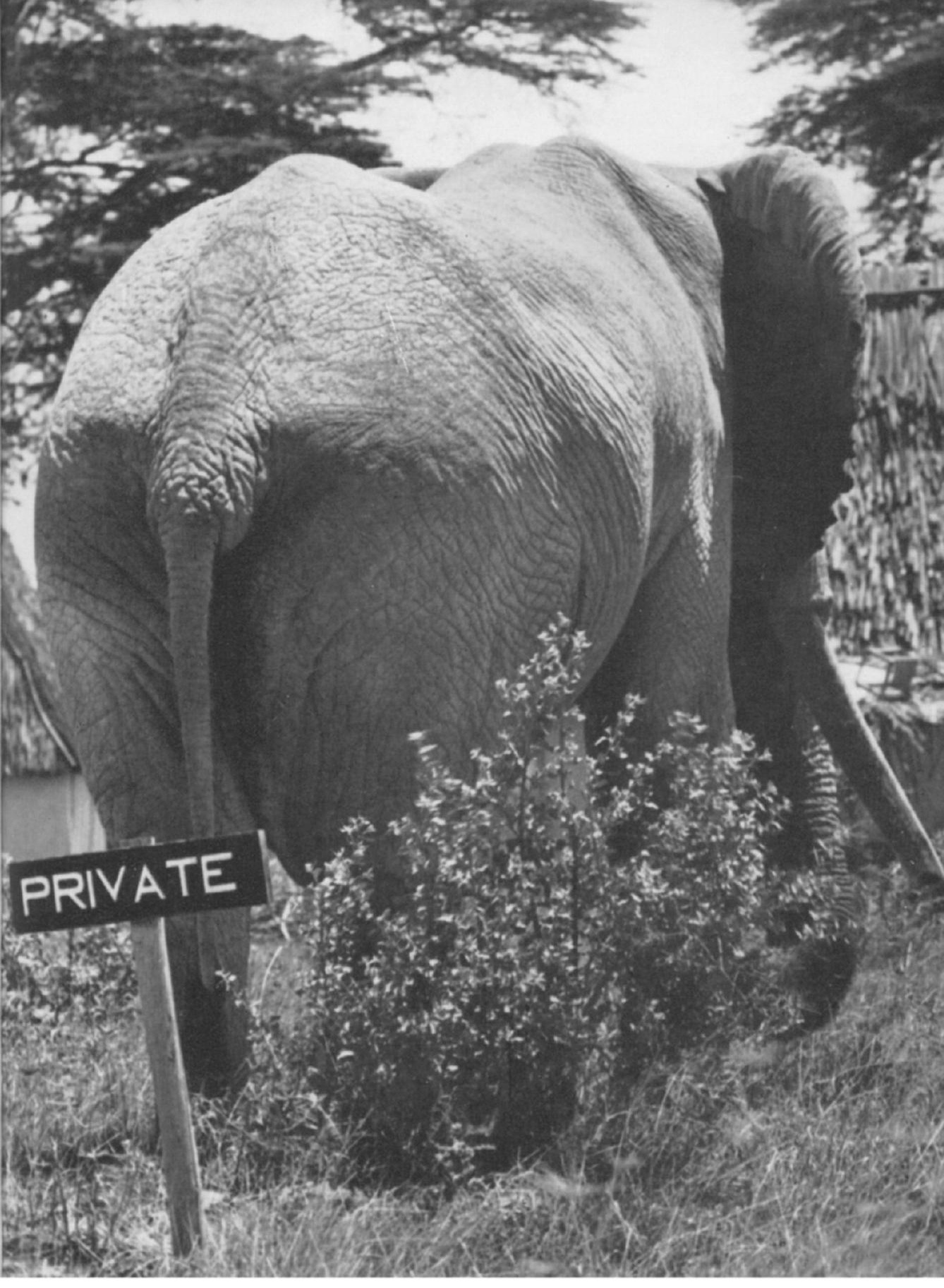

\section{MUCH SHE CARES! \\ Norman Myers}




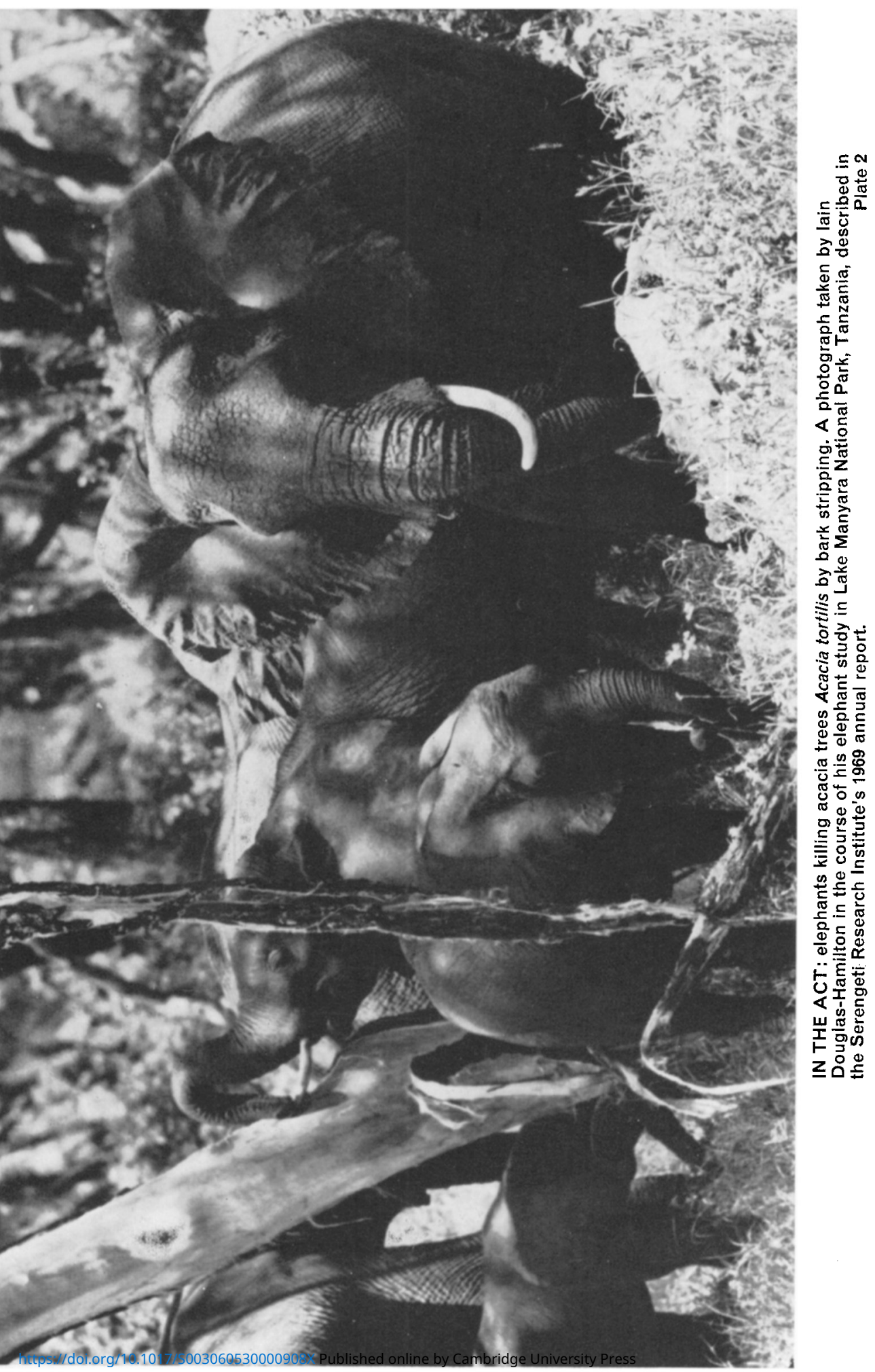


under the influence of elephant and fire and the southern and western border advancing in the face of fire, but few or no elephant. In the northwestern part of the Queen Elizabeth Park, where fire is frequent, Acacia regeneration has been strikingly apparent in recent years; this has coincided with the closing of an elephant corridor, from the Park to the Ruwenzori Mountains, due to human settlement in recent years, and a consequent reduction in elephant usage. In the Serengeti, in the face of frequent fires, $7 \mathrm{I}$ per cent of trees in ten study areas were less than $3 \mathrm{ft}$ tall (Lamprey, Glover, Turner \& Bell, 1967). Their large rootstocks suggested that their growth was suppressed-but it is evident that fire alone does not destroy them. In Tsavo, although quantitative vegetation studies are lacking, there are areas where the vegetation has not been burnt in recent years, but where regeneration is absent despite high rainfall, and the bush heavily pruned. The conspicuous difference between two sides of the main Mombasa Road where it forms the park boundary is striking in places. On the park side there is open bush or grassland, on the other side thick bush, yet the chances of fires starting are higher on the populated side. This indicates that in this habitat a great deal of thinning by elephants is necessary before fire can make any inroads.

Most 'elephant problems' appear to have been recognised only when obvious habitat damage was well advanced, and generally accepted only when severe barking, pushing over or destruction of large trees has occurred over wide areas. At this stage it is generally observed that there is little regeneration of young trees or bush. This is often attributed to fire, or to successional, climatic or hydrological changes (unspecified)the mature, dying trees are held to be 'time-expired'. Owing to lack of historical records there is often very little evidence to support opinions invoking the last three factors.

In many areas, elephant show a preference for varied young successional growth and their optimum habitat might well be in the ecotone between forest (or woodland) and grassland, or open bush. A preferential destruction of the understory including young regeneration occurred in the Murchison Falls Park (Buechner \& Dawkins, I96I), in the Budongo Forest (Laws, 1968a), and in the Ruaha National Park, Tanzania (Savidge, 1968, and personal observation). It has evidently occurred in parts of the Tsavo National Park, in the Amboseli Reserve and elsewhere, though apparently not in the Serengeti National Park. However, the invasion of the Serengeti area, induced by human population pressure, is fairly recent and it may be that it is not really an attractive habitat for elephants. If it were, we would perhaps expect a rapid expansion of the elephant population in the midst of plenty, particularly in the wet years since 196I, since there is a large area of woodland and elephant densities are low. The results of aerial counts in recent years suggest, at the most, stability in numbers but a shift in range (Watson \& Bell, 1969). On the assumption that it is not a favourable habitat for elephant, one might expect further counts to show declining numbers as natural regulatory processes come into operation. Only time, or the examination of a population sample, can show if this is the case. 
We may often be wrongly assessing a late stage in the process of habitat change as an early one, when in fact the regeneration, on which the replacement of mature stands depends, has been preferentially removed by elephant. This could fairly easily be determined by appropriate sampling and experiment. The concept of grazing succession (Vesey-Fitzgerald, 1960) is thought to apply (as a browsing succession) to elephant use of habitats. Under natural conditions it is considered that, as elephant populations modify a habitat by their activities, and natural regulatory changes in the population dynamics develop, there is also a general displacement of the population to other areas. With the occupation of land by man outside national parks, this pattern is reversed, the habitat modification becomes extreme, and regulation of their population dynamics alone is too slow (having evolved in natural situations) to prevent this.

It thus seems reasonable to conclude that both elephant and fire (as well as man) are responsible for the observed changes; that elephant damage is the primary (and continuing) factor which, by thinning the bush, suppressing regeneration, and allowing grass cover to develop, supplies fuel and allows fire to penetrate. Where the situation has developed to a late stage the control of one without control of the other will usually be ineffective.

The demonstration that there are density-dependent, natural regulatory processes acting on the elephant's reproductive cycle (Laws \& Parker, 1968; Laws, 1969a), and the assumption that there are selfregulatory behaviour patterns has been cited as another reason for delaying a cropping programme in Tsavo. 'We must not set about altering behaviour patterns until they have been studied and a norm observed' (Harthoorn, 1966). However, it has been shown that in Murchison Falls Park the natural regulatory processes, which have been long-term and drastic (including considerable retardation of age at first breeding and reduction in the calving rate by up to 50 per cent), have not yet been adequate to halt the habitat change or to stabilise the elephant population.

\section{Effect of Poaching Control}

In Tsavo, the release of the pressure from poaching (which may be thought of as illegal and uncontrolled cropping) appears to have resulted in a temporary population increase of elephant, at a time when the range available was decreasing, and may have been a significant (if unwitting) contribution to the development of the present situation. The limited evidence from the recent studies in Tsavo suggests that, in the face of considerable habitat modification, there have so far been relatively slight homeostatic changes in the population dynamics of the Tsavo elephant populations. By comparison with the other populations studied, it seems probable that the full effects of the regulatory changes will be considerably delayed ( 15 to 20 years) in several of the elephant populations using the Tsavo ecological unit. The habitat changes can be expected to continue and probably to accelerate.

The recent studies indicate that the growth of elephant population 
probably follows an S-shaped curve, and for the purpose of analysing overpopulation, the logistic equation is useful because it contains a parameter which can be equated with 'carrying capacity'. An often expressed criticism of the logistic equation is that it is empirical, but this is no great disadvantage in the present context. The theory assumes that populations grow towards a finite upper limit (carrying capacity), set by the area, resources and other parameters of the environment. In a population introduced into a new environment, growth is initially rapid, but, as the population grows, increasing 'environmental resistance' slows down the rate of increase until the population is in approximate equilibrium. In the case of elephant, the slowing down in response to environmental resistance is brought about by the changes in reproductive patterns described, and probably also by increased calf and adult mortality.

In a uniform habitat, reduction in the area available to the population will cause a proportionate decrease in carrying capacity. Provided there is sufficient time for regulatory mechanisms to come into operation the population will come into a new equilibrium. But suppose that the area available decreases more rapidly than the population regulatory response can come into operation; then population response will lag behind and there will be a period when the habitat will be over-used and damage may ensue. If this is not too serious, or prolonged, or if the climatic component of the environment improves, then a new balance may be reached. However, if the habitat damage is considerable, or if there is a reduction in rainfall (for example), then we may find a progressively worsening situation with the carrying capacity decreasing at an increasing rate and, in turn, habitat damage increasing rapidly. This could, in an extreme case, lead to the carrying capacity for a particular species in that area falling to zero-as for elephant if Tsavo became a near-desert. In the process, the carrying capacities for other species could change in a similar way. A similar process could start with an equilibrium population, and respond in a similar way to the deteriorating habitat.

This is, of course, an over-simplification for the purpose of discussion; for one thing, the response would not be smooth but would reflect climatic fluctuations, variations in the rate at which the available area decreased, and the suppression of predation (poaching). But it serves to clarify thinking on the 'elephant problem' and serves as a basis for the construction of population models. It also means that, if elephant population growth is adequately or approximately described by the logistic, and if we can obtain estimates of two parameters (the intrinsic rate of increase and population size), then an approximate carrying capacity can be calculated. Preliminary estimates suggest that this is about I.5 to 2.0 elephants per square mile for the areas studied in Tsavo before the habitat change; that is much higher than Glover's (1963) estimate. If reduction cropping were to be undertaken it should, therefore, aim at reducing the population so that it would be brought to a level below the carrying capacity in as short a time as possible. The fact that we have just passed the peak of a rainfall cycle (Laws, 1969a), 
suggests that we may expect a more rapid decline in carrying capacity within the next few years and elevation of the elephant problem from chronic to acute crisis proportions.

The immediate need is for detailed studies on the dynamics of the Tsavo elephant populations, by means of the scientific sampling programme proposed by the Research Project in 1967, which would involve the taking of some 2400 elephant from eight populations, and their examination. Some I 500 to 1800 would have to be sampled within the national park. This would indicate to what extent the various populations were regulating. Cropping on this scale, representing less than Io per cent of the populations concerned, would not, if properly carried out, carry any threat to the survival of the elephant populations, nor could it appreciably affect the habitats. It is essential to obtain the information on which to base management decisions.

\section{Sampling without Disturbance}

The problem of large-scale sampling has been solved by Wildlife Services Ltd., who have been responsible for taking 2000 elephants in the Murchison Falls National Park, 300 in Tsavo and 300 in Mkomasi*, Tanzania, with virtually no disturbance. The taking of random samples by complete elimination of population units (family units and bull herds), minimises the likelihood of behavioural disturbances or interference with the regulatory processes. Certainly the fears expressed by preservationists that wounded elephant may escape out of the park, that 'the effect of large scale cropping on the habitats of the parks' elephant is unpredictable', and that 'it might make them savage', that the disposal of the carcasses is an enormous problem, and 'the disturbance factor on the elephant herds incalculable' (Harthoorn, I966) are unwarranted, and Harthoorn agrees that 'it is almost certain that control of the elephant will have to effected'. These operations have been carried out without these predicted effects, thus removing one of the many 'red herrings' that have bedevilled the Tsavo problem.

As regards subsequent reduction-cropping, if this is agreed to be necessary, the demonstration that there are a number of discrete elephant populations simplifies the management problem because they can be treated as separate problems. Some, in areas where the change to grassland is far advanced, could be left undisturbed as natural experiments to continue their regulatory processes; but others should receive attention in an attempt to retain areas of Commiphora-Acacia bush, baobab stands and other habitat types. On the evidence now available, the alternative to cropping is, at best, a continued erosion of habitats and of animal populations dependent on bush; at worst, a continued habitat deterioration, a prolonged population crash and the miserable protracted deaths of thousands of animals.

The fact that the vegetation change is undisputed and has been proceeding for some time, and that studies leading to predictions will necessarily be of long duration tends to detract from their urgency. But clearly, if the full value were to be obtained from the experimental

* Another sample of 300 was examined in the Mkomasi reserve in 1969. 
reduction of elephant populations, it would be necessary to record the habitat response. At the same time the plant ecological studies proposed earlier should be set in train, and in particular the special study of the influence of fire and its control.

\section{References}

BUECHNER, H.K. and DAwKINs, H.C. (I96I) Vegetation change induced by elephants and fire in Murchison Falls National Park, Uganda. Ecology, 42, 752.

Glover, J. (1963) The elephant problem at Tsavo. E. Afr. Wildl. fnl. r, 30. HARTHOORN, A.M. (I966) The Tsavo elephants. ORYX, 8, 233.

LAMPREY, H.F., Glover, P.E., TURNER, M.I.M. \& BELL, R.H.V. (1967) Invasion of the Serengeti National Park by elephants. E. Afr. Wildl. Fnl., 5, $15 \mathrm{I}$.

Laws, R.M. (1968a) Interactions between elephant and hippopotamus populations and their environments. E. Afric. agric. For. $\mathscr{f} n l, 6$ (in press).

Laws, R.M. (1969a) Aspects of reproduction in the African elephant, Loxodonta africana. F. Reprod. Fert. Suppl. 6, I93.

Laws, R.M. (1969b) The Tsavo Research Project. F. Reprod. Fert., Suppl. 6, 495 .

LAws, R.M. and Parker, I.S.C. (1968) Recent studies on elephant populations in East Africa. Symp. zool. Soc. Lond. 21 .

PRATT, D.J. (I966) Bush-control studies in the drier areas of Kenya. II. F. Appl. Ecol. 3, 97.

SavidGE, J.M. (1968) Elephants in the Ruaha National Park, Tanzania: A management problem. E. Afr. agric. For. F. 33, 19 I.

VeSEY-FITZGERALD, D.F. (1960) Grazing succession among East African game animals. f. Mammal., 4I, 16r.

Watson, R.M., Parker, I.S.C. and Allan, T. (1969) A census of elephant and other large mammals in the Mkomasi region. $E$. Afr. Wildl. F., 7, $1 \mathrm{r}$.

\section{Rescues in Rhodesia}

Rescue operations for black rhinos, eland and crocodiles have all been undertaken by the Rhodesian Wild Life Management department this year, the first two considerably aided by public subscriptions. Forty-five black rhinos have been captured in areas where they were in danger and taken to re-stock the Gona re Zhou game reserve, in south-east Rhodesia, once a favourite haunt of this rhino. They were exterminated there when the last one fell to a poacher in 1934 .

The eland operation involves a herd living close to the small Chimanimani National Park, on Rhodesia's eastern frontier. These animals occasionally do severe damage to the pine forests, where much commercial timber is grown. To protect the eland from the wrath of the foresters and also from poachers, a sanctuary is being fenced off outside the park, and I500 beaters will drive the eland into it.

Crocodiles, which are decreasing in numbers all over Africa, are being rescued from rivers where they are in danger (usually as a result of their preying on domestic stock). As soon as the department hears of trouble with a large crocodile, a team of catchers is sent out to collect and remove the offender to a river in a remote area where it will be undisturbed and can find its natural food. So far thirty such crocodiles have been successfully translocated. 